\title{
Mrs Bottomley's Ten Point Plan
}

\author{
Tom Burns
}

The government's proposals for Legal Powers on the Care of Mentally Ill People in the Community. commonly referred to as Mrs Bottomley's Ten Point Plan, were published in August 1993 (Department of Health, 1993). The official team was formed after a meeting between the Secretary of State, the Royal College of Psychiatrists and a number of other interested parties in the first week of the New Year after the Ben Silcock incident. The team of 12 was required to complete their work within six months. Its terms of reference were:

to consider urgently, in the light of the College's proposals: whether new legal powers are needed to ensure that mentally ill people in the community get the care they need; and whether the present legal powers in the 1983 Mental Health Act are being used as effectively as they can be, and what action could be taken in advance of any new legislation to ensure that they are.

The College's proposal for a Community Supervision Order (CSO) (Royal College of Psychiatrists, 1993), published in January 1993, was identified as the starting point for the review body's work. Although the review's brief was to examine the issue of the legal powers, they recognised that this could not be done without "taking account of the wider context in which the great majority of mentally ill people are now looked after in the community". As well as conclusions, and the recommendations set out in Table 1, their document covers:
(a) nature and scale of the problem
(b) current legal position
(c) service provision
(d) experience of other countries
(e) views of those consulted
(f) for and against a new power
(g) what kind of power?
(h) more effective use of existing powers
(i) resource implications

\section{Supervised discharge}

The College's CSO was eventually rejected by the review body. Their rejection appears to stem from concerns about the status of patient consent given in such circumstances and a belief that the
CSO proposals would result in the compulsory return to hospital of patients who had stopped taking their medicine but were otherwise 'well'. Such a reduction in the threshold for admission would contravene article 5.1 of the European Convention on Human Rights. This broadly requires that for detention a patient must actively demonstrate unsoundness of mind and that the detention ceases to be valid when the mental disorder disappears or ceases. Despite this, the review quotes a 1988 decision by the European Court in favour of the Swedish Discharge Council which seems indistinguishable from the powers suggested by the College.

Supervised discharge "includes the key features of guardianship" and "embodies the principles of the care programme approach". It requires a named key worker, a clear treatment plan negotiated with the patient plus the power to require the patient to reside at a specified place, afford access to those involved in his or her care and to "attend for medical treatment, occupation, education or training". Those involved would have the power to convey the patient to the place of treatment. Authority for its imposition will rest with the Responsible Medical Officer (RMO) "after consulting with others involved in (the patient's) care". The conditions for its imposition, duration and rights of appeal will be as those for section 3 of the 1983 Mental Health Act. There is no proposed absolute time limit.

As described supervised discharge should fulfil the functions envisaged for the College's CSO. The crucial test will be whether the RMO is able to say to patients that they have to take the treatment. Careful reading of the wording suggests that this will be legal although it will be interesting to see it challenged (as it undoubtedly will be) in a court of law. The review body has gone to great lengths to emphasise that the consequence of patients failing to comply will be a review of their liability to detention and not an automatic return to hospital. This was also spelt out in the College's proposal but unfortunately not as clearly.

\section{The other nine points}

The decision to seek an extension of leave of absence on section 3 from six months to one year 
1. Strengthened powers to supervise the care of patients detained under the 1983 Mental Health Act who need special support after they leave hospltal. These comprise:

(a) the new power of supervised discharge; and

(b) extending from six months to one year the period during which patients given extended leave under existing arrangements can be recalled to hospital.

2. Publication of the Department of Health team's report of its review of the 1983 Mental Health Act.

3. Publication of an improved version of the Code of Practice, which spells out clearly the criteria for compulsory admission under the 1983 Act.

4. Fresh guidance to ensure both that psychiatric patients are not discharged from hospltal inappropriately, and that those who leave get the right support from the different agencies.

5. Better training for key workers in their duties under the care programme approach. This will cover the new Code of Practice and guidance, and will take account of the lessons from the cases which have gone wrong, and from the Royal College of Psychiatrists' confidential inquiry into homicides and sulcides by mentally ill people.

6. Encouraging the development of better information systems, including special supervision registers of patients who may be most at risk and need most support.

7. A review, by the Clinical Standards Advisory Group, of standards of care for people with schizophrenia, both in hospital and in the community.

8. An agreed work programme for the Government's Mental Health Task Force, which supports health authorities in moving to locally-based care.

9. Ensuring the health authority and GP fund-holder purchasing plans cover the essential needs for mental health services.

10. The London Implementation Group will take forward an action programme to help improve mental health services in the capital, identifying and spreading best practice.

(point 1b) will be welcome to most psychiatrists. This should enable teams to build on the symptom stabilisation which has been achieved by a compulsory admission.

The commitment to improved training both for key workers in the care programme approach (point 5) and for doctors, nurses and social workers in ensuring that the Act is properly understood is surely to be welcomed. The inconsistency with which psychiatrists were reputed to interpret the Act was repeatedly encountered as a source of resistance in the College's consultations. We would be well advised to take up the proposal.

The development of better information systems (point 6) is crucial to effective community care of the mentally ill. Flexible, reliable computerised databases which identify those patients most at risk will undoubtedly improve care. Mrs Bottomley's group only talks of 'encouraging' their development. This is not enough. The resource implications are obvious and the review body's integrity will be judged, in part, by its commitment to developing and providing such information systems.

The remaining points are mainly restatements of the importance of ongoing work often expressed as uncontroversial vague targets - "take forward an action programme", "fresh guidance to ensure ... patients are not discharged inappropriately", "a review ... of standards of care" etc.

\section{Conclusion}

Careful reading of the ten point plan suggests that there is no great difference in practical terms between the review body's proposals and those initially advanced by the College. There is an undertaking to pursue legislation which will in the short term extend leave of absence and eventually provide a framework for ensuring that a small, but very vulnerable, group of patients are obliged to comply with treatment without having to be detained in hospital. That the proposal comes from the government rather than the profession may prove to be a major blessing.

\section{References}

Department of Health (1993) Legislation planned to provide supervised discharge of psychiatric patients. Press release $\mathrm{H93/908,} 12$ August.

RoYal College of PSYchiatRISTS (1993) Community Supervision Orders: London: Royal College of Psychiatrists

Tom Burns, Professor, Community Psychiatry Section, Division of General Psychiatry, St George's Hospital Medical School, Jenner Wing, Cranmer Terrace, Tooting, London SW17 ORE 